\title{
A Conceptual Model for Empowering Families in Less Affluent Countries Who Have a Child With Autism
}

\author{
Sayyed Ali Samadi, Hadi Samadi and Roy McConkey \\ Additional information is available at the end of the chapter \\ http://dx.doi.org/10.5772/59111
}

\section{Introduction}

International experience has demonstrated that children with ASD can be helped and that families are crucial to the success of any interventions. In less affluent countries families play an even more crucial role given the dearth of professionals trained in ASD and appropriate support services [23]. In such countries, indigenous research is crucial to fully appreciate the needs of families and the most relevant means of empowering them to face the challenges posed by their child's condition. The outcomes of these research endeavours can then guide practitioners and policy makers in devising services best suited to local needs. Conceptual Models (CMs) are critical both to guide and validate the style and direction of research studies that are undertaken as well as synthesising key factors in shaping the type of support services provided for families. In this respect CMs have the potential to integrate research and practice.

The reason for considering CMs in any scientific field is to provide an explanation for existing relationships among the phenomena under investigation and to provide insights that may lead to the discovery of new relationships [32]. A Conceptual Model (CM) can be considered to be both as a synthesis of extant knowledge on the topic but also a guide for further studies. Sometimes the phenomena under investigation are so complex that no one CM can exclusively provide the necessary guidance. Research on families-specifically families who have a member with disability-fit into this category. It is the main objective of this chapter to discuss and demonstrate how facing new problems in the course of an evolving programme of research, encourages researchers to further develop their initial CM in order to arrive at a more comprehensive account of the phenomena they are investigating: a necessary outcome in order to guide practitioners in new areas of work such as Autism. Otherwise the risk is that the services they deliver - either as an individual clinician or within a service system such as education is based on incomplete and out-dated models. The chapter draws on a series of studies 
undertaken by the first author initially for his doctoral thesis but continued in his post-doctoral research. As a clinical psychologist, he had previously worked in services for persons with intellectual and developmental disabilities on assessment and rehabilitation programmes.

The study started with two main aims: 1) to enhance current knowledge on the impact of taking care of a child with ASD on family dynamics in Iran; and 2) to help parents in reducing negative effects of raising a child with ASD through short educational courses and extending their social network through providing opportunities for meeting each other. He first undertook a survey of parents' experiences in Tehran to having a child with ASD [21] and how the personal impact on families differed from those with a child who had intellectual disabilities [27]. From this study, an introductory training course on ASD for parents was devised and evaluated [25]. The longer -term impact of such a course was also assessed and the contribution that mutual support from other parents can make to maternal well-being in particular [15]. Further resource materials to inform and guide parents were developed - DVDs, educational packs and the provision of educational materials [27].

\section{Identifying appropriate conceptual models}

There is no unique scientific method to guide the process of empirical enquiry. Likewise, there is no distinctive conceptual model that can be applied in all research programmes of family studies. So, the aim of this chapter is NOT to build up an all-embracing model in such a complex area as family environment. No one model would be sufficiently comprehensive that it could guide all future research. However, without adopting some form of CM no research could be done and so, adopting a CM is the first and indispensable part of research that no researcher could avoid even if they never make explicit the CM that underpinned their study which in fact frequently happens.

But how does a researcher choose among the competing CMs that are available and which are likely to prove suitable for other cultures? Again, there is not a single and simple guideline to help the researcher's choice. This is a tricky and potentially fallible step and one that has to be informed by the chosen topic of the investigation, the extant literature on it and the experiences gained personally by the researcher and in consultation with practitioners and families who have the lived experience of the chosen phenomena. It is some consolation to know that the $\mathrm{CM}$ initially chosen often is found to have shortcomings when it is put into practice. Abandoning the chosen $\mathrm{CM}$ and adopting another one is not a good recommendation most of the time; especially when the chosen CM has enabled us to deal with certain aspects of the problem. The better solution is to extend the CM to encompass newly identified issues. By offering an example around parental empowerment that might be useful to others, we aim to show how the formation of a more complete $\mathrm{CM}$ can be achieved. In so doing, we hope to draw out the ways in which this case study could assist practitioners and also the future research questions that can emanate from it. 


\section{Parental empowerment}

In developing countries parental empowerment is a relatively new term in the literature on children with developmental disabilities. Yet involving parents in the process of promoting their child's development seems to be the most rational solution to the lack of support and services for this group of children and their families. Even in developed and more affluent societies, parental empowerment is a growing concern as [18] point out. Financial constraints and changing ideologies have expanded parents' roles to include the jobs of "information seeker, problem solver, committee member, public educator, political activist and, most importantly, spokesperson for the needs of their children".

Empowerment has been defined as "an intentional, ongoing process ... through which people lacking an equal share of valued resources, gain greater access to and control over those resources" (Cornell Empowerment Group, 1989, p. 2 cited in [19] The word 'intentional' refers to the psychological aspects of empowerment; 'ongoing process' refers to the likely up and downs that will be encountered as well as the need for persistence of over time; 'lacking an equal share of valued resources' refers to the societal aspects that disadvantage families and 'greater access to and control over' summarises the intended outcomes.

The first challenge was to find a CM that could be adopted so as to empower parents of children with ASD in Iran. Part of the difficulty with research on topic of parental empowerment is that it is context and culturally dependent [35]. This makes it a real challenge to find a universal model of parental empowerment.

However there are some general criteria that can guide the choice among available CMs. Simplicity, wideness of scope and easiness of applicability may be among these criteria (see [16] for the virtues of a good theory). However, such criteria may be too general; appealing more to philosophers of science and can appear trivial especially in assisting practitioners in their choice of CM.

The following criteria were used to select appropriate CMs for research into parental empowerment in Iran:

- Concept of disability: the CM had to reflect current thinking about disability, such as that reflected in the International Classification of Functioning, Disability and Health (ICF) [34].

- Social Cultural issues: the CM had to consider the impact of social context, cultural influences and attitudes;

- Compatibility with family centred approach: the CM had to be compatible with family centred approaches as international experience has identified this as key to effective intervention for children with developmental disabilities.

We now examine each of these in more detail. 


\section{Concepts of disability}

ASD is predominantly conceived as a medical condition based on DSM or ICD definitions. The medical model tends to believe that the curing or managing of disability generally or completely, revolves around identifying the illness or disability from an 'in-depth' clinical perspective involving doctors, therapists and psychologists. The irony is that ASD even in the medical sources is defined based on its behavioural manifestation rather than clinical symptoms. Sole reliance on a medical condition sits outside modern conceptions of disability that acknowledge environmental influences such as family and society on a child/person's level of functioning. These may be particularly crucial in developing countries with their poor service infrastructures at local and national.

The International Classification of Functioning, Disability and Health (ICF, WHO, 2002) is an updated framework for the description of health and health-related states. The classification is focused on health and health-related domains based on what a person with a health condition can do in a standard environment compared to what they actually do in their usual environment (comparing the level of capacity to the level of performance). Thus social and environmental factors can have a major influence on a child's level of functioning in addition to any medical and disability condition.

The ICF also embodied the thinking in the bio-psycho-social frameworks which have been proposed in disability and mental health in which different biological, psychological, and social influences are brought together [8]. As Engel argues there is a reciprocal rather than a linear relationship between all these three main factors. According to this model, although a specific disability may require primary attention at the biological level - such as hearing impairment-it will also have an impact on psychological factors and both factors in turn may influence the social system of the person with disability and their parents. Thus ICF provides a comprehensive view of factors involving health, illness and health care and explains and understands individual behaviour in particular contexts.

\section{Social and cultural factors}

$[1,2]$ ecological framework of the different systems that impact on a child's development, could also help researchers and practitioners to better understand the situation of parents who are taking care of a child with ASD. He posits five different systems that can influence childhood development: the Microsystem, Mesosystem, Exosystem, Macrosystem and Chronosystem. A change in any one of these components can cause a change in the other components. Microsystems are those closest to the child-such as family and school-as they directly impact on the child. These Microsystems are interrelated and together form a higher level system: the Mesosystem. However these take place within an Exosystem of community services and supports that in turn is influenced by the wider cultural Macrosystem, including ideologies, laws, economic and social policies and religious attitudes. All of these systems and the interactions between them can change over the course of a child's life which is captured in the concept of the Chronosystem. 
As [33] argued, in an ecological model the main emphasis has to be on "fixing" the multiple ecological environments, rather than "fixing" the child with disability and having him/her fit into different social layers of family, community and society, which is the aim of the medical model. This suggests a shift of attitude to change the focus away from the child with disability as an independent entity towards a more global view which covers both children and their families. According to an ecological model, the focus is on a transformed ecology in which children with different types of disabilities can develop by using their skills in interaction with a responsive environment [33].

\section{Family-centred interventions}

There is also a shift from child-focussed interventions to family-focussed interventions. Family-centred practice is an umbrella term for both a philosophy and a method of service delivery consisting of a set of values, skills, behaviours and knowledge that recognises the centrality of families in the lives of their offspring. It puts family life, the strengths, needs and choices of people with a disability and their families as the focal point of service planning, development, implementation and evaluation. It is grounded in valuing the uniqueness of every person and family, and a commitment to partnering with families and communities to support children and young people with developmental delay or disability to learn, grow and thrive.

Family-centred approaches value the strengths and resourcefulness of all families and aims to support and encourage families in their efforts to meet the special needs of their child with a disability and of the parents in ways that are defined as independent, functional and appropriate [4].The efficacy of family-centred practice has been well demonstrated in affluent countries [7] and applied across all developmental disabilities but may be less well developed in ASD.

With these criteria in mind, the three most promising frameworks for family empowerment were found to be: 1) Bronfenbrenner's theory on human ecology [1, 2], 2) the McMaster Model of family functioning [9, 10, 11], and 3) Enabling and Supporting Families [6]. Although other frameworks have been applied in family research, they were considered to be insufficient for the purpose of the research study undertaken in Iran. For example, the Lazarus Theory on Stress and Coping (Lazarus, 1966 cited in [14] had been used in many studies on parental stress and coping. Although this theory conceptualizes stress as an outcome of the relationship between individuals and their situation as parents of a child with disabilities, it emphasises more the personal rather than the social side of stress and coping.

\section{Amending the adopted model and combining with other CMs}

The three identified models raised a fundamental issue. How would the researcher choose between them and which one should he choose? Were these CMs rival or complimentary to one another? In fact the answers came as part of an evolving process during the course of the 
research. The most credible solution was to try and combine the three available conceptual models. In addition he also had to supplement the model to elaborate the concept of empowerment.

Initially Bronfenbrenner's theory on human ecology seemed sufficient as it brought together the insights from the other two approaches and provided a general picture of society with respect to its different layers in order to explain interactions between the components of the microsystem level and wider society. However our literature searches allied with the authors' experiences identified some limitations. Although this model stresses the relationships between various components within different social layers, it does not help us to fully explore and understand the relationship among the family members.

Thus the McMaster family functioning model was used as an extension of the ecological model. The main reason for adopting the family functioning model was to consider the family as the unit of analysis in the research. Although Bronfenbrenner's theory is based on systems theory, inherently it is an individualistic approach whereas McMaster theory has a holistic perspective and focuses on the family and the impact of disability on all members of the family - notably mothers and fathers. The main focus is on present problems not past origins which can be considered a particular concern for clinicians and practitioners. The emphasis is for family members to address present concerns, resistances, or blockages so as to find solutions for their problems. When using the McMaster approach, the practitioner functions as a catalyst, clarifier and facilitator. The goal is to help family members to identify and solve problems themselves.

However the Family Functioning model alone was insufficient in understanding how this problem solving process might be done. The addition of Dunst's family support model further extended the model by including the types of support - formal and informal - that are beneficial to families. But important as this was in identifying the range and level of supports across systems, in itself it did not focus on the process of empowerment a point we will come back to later.

A word of caution relating to merging CMs. In extending a basic CM to cover some merits of another one there should be some semblance in their background and overlaps between them. The CMs in this study recognised the core role that family relationships had within other systems such as the extended family, school and religious systems. These levels of similarity provided a basis for extending the ecology model to encompass aspects of the McMaster, Enabling and Empowering Families CMs.

Within each of these domains specific aspects that researcher had found to be especially relevant for parents' empowerment in Iran were highlighted. Moreover it is the combination of these different perspectives that is the main and novel feature of the proposed model in this paper.

Also it could be argued that we should separate the questions of our research at the outset and answer them in the context of separate and suitable conceptual models. Sometimes this may be a good recommendation. However, in some instances, especially in times of dealing with complex phenomena such as parental empowerment, a more comprehensive understanding of the subject will not occur by separating the questions that are actually deeply related and 
answering them in unrelated CMs. Our suggestion is that in such cases expanding the chosen $\mathrm{CM}$ to encompass other related questions is a better strategy.

\section{Focus on empowerment}

As Shultz et al., 1995, suggests empowerment can exist at three main levels: individual, organizational and community level. This became apparent in the different stages of the research programme.

Each of the three mentioned CMs has its own advantages for dealing with one of Scultz's levels. A variation of a "family systems model" is the McMaster model of family functioning (MMFF), described by [10] in the mid-50s. This outlines the basic concept of family functioning [17] and is based on the theory that the primary function of the family unit is to provide a setting for the development and maintenance of family members on the biological, social, and psychological levels [10]. Over a period of thirty years this model has evolved and the reformulations of it have tried to overcome some of the problems that emerged in the initial application of the model [17]. It facilitates empowerment at an individual level. Empowerment at this level entails psychological processes such as parental wellbeing, coping strategies and self-esteem.

Likewise an understanding of the socio-political environment, which includes knowledge of the laws and an appreciation by parents of their rights and responsibilities with respect to their situation helps with organizational empowerment. This level of empowerment enhances goaldirected actions by members of a group or organization. A model plays an important role at this level of empowerment. This was provided through the model of Enabling and Empowering Families. In this CM available sources of help are also important. [5] argue that a better relationship between parents, service providers and professionals increases the level of empowerment. Iranian parents in these studies were asking for more and improved professional services for their children and themselves. Therefore, at this stage of research, examining the service delivery-related factors that influence family empowerment was particularly helpful.

Finally at the broad level of community, empowerment reflects actions taken by a group of people to improve life in their society. The ecological model clearly explains this concept and defines approaches for helping families to strengthen their abilities to provide their children with experiences and opportunities similar to other children with regular development. Parents were asking for development-enhancing qualities above the individual or organizational level and were hoping to change the dominant attitude of the society and the stigma that resulted from having a child with ASD. This happened when a group of parents who were participants of the studies went on to form a non-governmental organisation for Autism to lobby for better services and to provide mutual support to families.This was the first Iranian nongovernmental association in this kind. 


\section{Further additions to the model}

There were still aspects in family empowerment that even the extended CMs could not deal completely with, notably how educating families produced changes in them. This needs additional conceptual insights which were provided by [13] and [12]. Although their theories had been initially developed for nursing education, the attractive aspect was the emphasis that education is more than knowledge acquisition and should lead to action. [13] suggested that learning through understanding one's own situation and abilities, is built around the processes of enlightenment, empowerment and emancipation. In the educational sessions parents understand "who they are", i.e., the "Enlightenment". The second process helps parents to "change" who they are, i.e., "Empowerment". Following this, the third main dimension is presented, i.e., "Emancipation", the process which helped parents to "become" what they wanted to be. This highlights the importance of education in bringing about changes in parents and their activities so that they have their own voice in changing the attitudes of their society. On the other hand relying solely on this model of empowerment would imply that the process of emancipation occurred for all parents to the same extent which was not true. For example the Parental NGO faced different system problems which caused serious crises for both the NGO and the members. Thus the broader model that had evolved was needed to account for the individual variations that remained and which were evident after as well as before the training such as the nature of the disability, family dynamics and community reactions. Again, it must be noticed that in extending a CM the auxiliary theories should have commonality with the main CM, or at least be consistent with it. Thus enlightenment, empowerment, and emancipation concepts can be construed as an elaboration of the family functioning model. In this model the primary function of the family unit is to provide a setting for the development and maintenance of the family members on the biological, social, and psychological levels. To be able to provide the necessary bases for family development, the family's needs and desires must be known. Parental awareness about their needs could be obtained through information provision, exchange of experience with other parents and letting them have their own voices to talk about their ideas and to explain things from their own perspective. Family enlightenment, empowerment and emancipation will be obtained by improving family functioning and their communication with one another along with fostering the emotional health of its members through information provision, exchange of experience and having their own voices through their own advocacy. Equally these three concepts could help us in understanding the improvement of family functioning levels through providing more opportunities for being influential in their society.

Figure 1 presents the resulting model to emerge from the research and development programme. Here we draw out the ways in which this model could assist practitioners and also identify further research questions that emanate from it.

Finding theories and models of family programmes is not a big challenge. The challenge is to adopt them in a way that is suitable to use in the context of the reality of the life of families and children with developmental disabilities in different societies. Similar approaches could be adopted to guide the development of clinical practice and services especially in less affluent countries. A useful starting point is the model that has evolved in Iran albeit within the context 


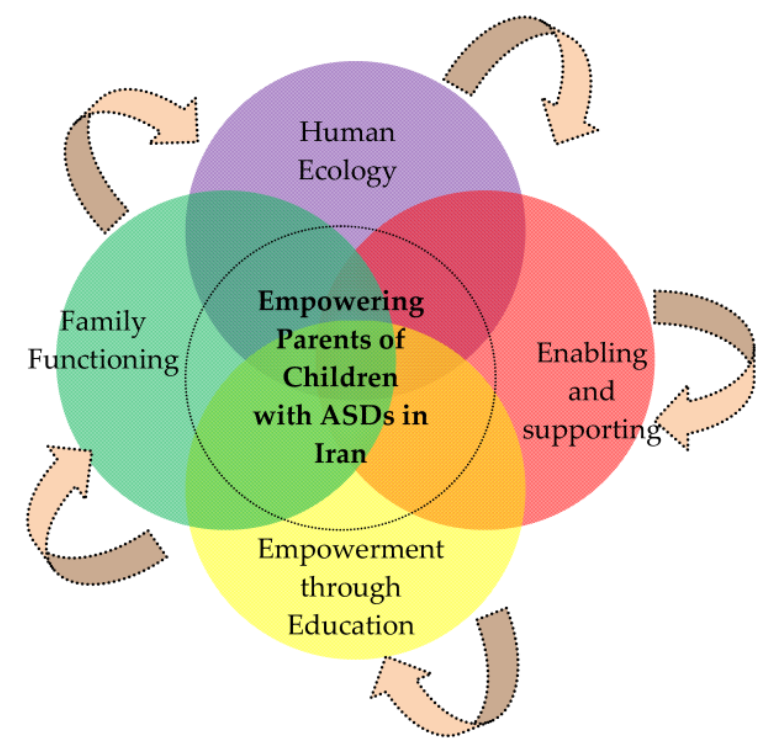

Figure 1. The final model which was used to answer the research questions that emanate from the thesis on "Parental Empowering".

of research. In recent years this process has begun and various strategies have been tested along the development of resources to support these new styles of working.

The following are some of the key components of service provision based on the integrated conceptual model.

- The focus should be on families and not just the child. Professionals visiting the family at home is one means for living this message even though initially it may go against cultural norms.

- Any assessment of the child needs to be informed by family interactions he or she experiences, the learning opportunities provided to the child and the possible social and environmental barriers impeding the child's development.

- Family-centred therapeutic interventions for ASD are devised which are undertaken mainly by families in home settings rather than by professionals in clinics.

- Knowledge transfer and the sharing of professional expertise is essential and can be done through the preparation of DVDs and books. Two books on Autism has been published in Farsi $[22,30]$.

- Training courses are devised and offered regularly to parents. One aim of such courses is for parents to learn from one another as a group on six to eight occasions.

- Parental advocacy is promoted and in this respect, the involvement of fathers can be especially helpful. 
- Greater public awareness of ASD is promoted through parental advocacy, use of media and briefing for community leaders.

In sum, the model envisages a community-based, family centred service based on partnership working among all the stakeholders.

Equally this model generates further research questions. Chief among them are the following:

- Are children with ASD who experience these styles of services more socially included within their families and community?

- If they are included, does this reduce their symptoms of ASD - are they socially more communicative with fewer behaviour management issues?

- Are the children able to gain entry to mainstream schooling and what supports are needed to sustain their placements?

- Can schools incorporate elements of this model by becoming more family and communityfocussed?

- Do parents who experience this model show sustained improvements in their family functioning and emotional wellbeing?

- How effective is this model for families living in rural settings?

\section{Conclusions}

Parents in most countries realise their important role in supporting themselves and their children despite financial constraints and changing ideologies [19] but in practice in the developing societies, their role is not clearly defined and their presence is not welcomed by clinicians and professionals. In these societies based on the dominant service provision for children with developmental disabilities, parents themselves preferred to act passively. In the case of ASD in Iran, parents still need to struggle to be trained and confident enough to be acknowledged and valued and to be recognised by the society as an integrated group. If the needs of families of children with ASD are to be met through parental empowerment, it seems that a more co-ordinated and coherent CM is needed. Since such a CM has not yet been developed, the family researchers, especially those who study more complicated families, such as a family of children with ASD, have to choose among the available CMs. The experiences which were mentioned here have also required other conceptual models and it could be argued that they have further validated the researcher's choice of framework in different studies on parental empowerment. The complex nature of empowerment has contributed to the adopted approach.

The nature of the phenomena under investigation urged the researcher to adopt different CMs. As the research went on, it became evident that the adopted CM had some limitations in dealing with aspects of the empowerment process in parents of children with ASD in Iran. In this case the adopted CMs need expansion each time to justify the findings. This expansion 
should be done with the aid of other conceptual models that are consistent with each other, and could cover conceptual shortcomings. Therefore this chapter could be considered as an attempt to specify a model specific to ASD within a tradition that incorporates social ecology, family functioning and parent empowerment.

\section{Author details}

Sayyed Ali Samadi ${ }^{*}$, Hadi Samadi ${ }^{2}$ and Roy McConkey ${ }^{1}$

*Address all correspondence to: s.samadi@ulster.ac.uk

1 Centre for Intellectual and Developmental Disabilities-Institute of Nursing Research, University of Ulster, N. Ireland, UK

2 Department of Philosophy of Science, Science and Research Branch, Islamic Azad University, Tehran, Iran

\section{References}

[1] Bronfenbrenner, U. (1979). The Ecology of Human Development. Harvard University Press.Cambridge,Mass

[2] Bronfenbrenner, U. (1989). Ecological systems theory. Annals of Child Development, 6, 187-249.

[3] Coreil, J. (2009). Behavioral and Social Science Theory. In Jeannine Coreil (Eds) Social and Behavioral Foundations of Public Health Second Edition (PP69-90). SAGE Publications, Inc

[4] Dempsey, I., \& Keen, D. (2008). A review of processes and outcomes in family-centered services for children with a disability. Topics in Early Childhood Special Education, 28(1), 42-52.

[5] Dunst, C. J., \& Trivette, C. M. (1987). Enabling and empowering families: Conceptual and Intervention Issues. School Psychology Review, 16, 443-456.

[6] Dunst, C. J., \& Trivette, C. M. (2005). Family resource programs, promotion models, and enhancement outcomes. Practical Evaluation Reports, 1(1), 1-5. Available at http://www.practicalevaluation.org/reports/cpereport_vol1_no1.pdf.

[7] Dunst, C.J., Trivette, C.M., \& Hamby, D.W. (2007). 'Meta-analysis of family-centered helpgiving practices research', Mental Retardation and Developmental Disabilities, vol. 13, pp. 370-380. 
[8] Engel, G. L. (1977). The need for a new medical model: a challenge for biomedicine. Science, 196(4286), 129-136.

[9] Epstein, N. B. Bishop, D., Ryan, C., Miller, \& Keitner, G., (1993). The McMaster Model View of Healthy Family Functioning. In Froma Walsh (Eds.), Normal Family Processes (pp. 138-160). The Guilford Press: New York/London

[10] Epstein, N.B., Baldwin, L.M., \& Bishop, D.S. (1983). The McMaster family assessment device. Journal of Marital and Family Therapy, 9,171-180.

[11] Epstein, N.B., D.S. Bishop, \& L.M. Baldwin. (1984). "McMaster Model of Family Functioning." In: D.H. Olson, and P.M. Miller, eds. Family Studies Review Yearbook, Volume 2. New Delhi: Sage Publications.

[12] Harden, J. (1996). Enlightenment, empowerment and emancipation: the case for critical pedagogy in nurse education. Nurse Education Today, 16(1): 32-37.

[13] Johns, C. (1995). Framing learning through reflection within Carper's fundamental ways of knowing in nursing. Journal of Advanced Nursing, 22, 226-234.

[14] Krohne, H. W. (2002). Stress and Coping Theories. Retrieved in 21 March 2013 from: http://userpage.fu-berlin.de/ schuez/folien/Krohne_Stress.pdf

[15] McConkey, R. and Samadi, S.A. (2012). The impact of mutual support on Iranian parents of children with an Autism Spectrum Disorder: A longitudinal study. Disability \& Rehabilitation. DOI: 10.3109/09638288.2012.707744

[16] McMullin, E. (2009). The virtues of a good theory. In M. Curd and S. Psillos eds., The Routledge companion to philosophy of science. Routledge.

[17] Miller,I.W., Ryan, C.E., Keitrner, G.I., Bishop, D.S. \& Epstein, N.B. (2000).The McMaster Approach to families: theory, assessment, treatment and research. Journal of Family Therapy. 22: 168-189.

[18] Minnes, P, Nachshen, J., \& Woodford, L. (2003). The Role of Families. In I. Brown and M. Percy (Eds.) Developmental Disabilities in Ontario (2nd Ed.). Toronto: Ontario Association on Developmental Disabilities, 663-676.

[19] Nachshen, J. S. (2005). Empowerment and families: Building bridges between parents and professionals, theory and research. Journal on Developmental Disabilities, 11(1), 67-75.

[20] Pereira, M. G., \& Smith, T. E. (2005). Evolution of the biopsychosocial model in the practice of family therapy. International Journal of Clinical and Health Psychology Vol. 6, № 2, pp. 455-467

[21] Samadi S. A. \& McConkey R.,(2011). “Autism in Developing Countries: Lessons from Iran," Autism Research and Treatment, vol. 2011, Article ID 145359, 11 pages, 2011. doi:10.1155/2011/145359 
[22] Samadi, S.A. \& \& Mahmoodizadeh, A. (2013). Omid early intervention resource kit for children with Autism Spectrum Disorders and Their families. Paper submitted to: Early Child Development and Care. DOI:10.1080/03004430.2013.788501

[23] Samadi, S.A. \& McConkey, R. (2011). Autism Spectrum Disorders. Dowran Publication. Tehran.

[24] Samadi, S.A. (2013). Children with an ASD. Practical guide for Parents and Professionals, Dowran Publication. Tehran.

[25] Samadi, S.A. and Mahmoodizadeh, A. (2012). Parents' reports of their involvement in an Iranian parent-based early intervention programme for children with ASD. Early Child Development and Care. DOI:10.1080/03004430.2012.749872

[26] Samadi, S.A. and McConkey, R. (2013). The utility of the Gilliam Autism Rating Scale for identifying Iranian children with Autism. Disability \& Rehabilitation. DOI: 10.3109/09638288.2013.797514

[27] Samadi, S.A.(2014) Omid parental educational pack and resource kit for Children with ASD and their parents.

[28] Samadi, S.A., McConkey, R. \& Kelly, G. (2012) Enhancing parental wellbeing and coping strategies through a family-centred, short course for Iranian parents of children with an Autism Spectrum Disorder. Autism. 1-16, DOI: 10.1177/1362361311435156

[29] Samadi, S.A., McConkey, R. (2012). The impact on Iranian mothers and fathers who have children with an autism spectrum disorder. Journal of Intellectual Disability Research. DOI: 10.1111/jir.12005

[30] Samadi, S.A, McConkey, R, \& Kelly, G. . ((2011). ). The information and support needs of Iranian parents of children with autism spectrum disorders, Early Child Development and Care, DOI:10.1080/03004430.2011.616931

Samadi, S.A., McConkey, R., \& Kelly, G. (2011). The information and support needs of Iranian parents of children with autism spectrum disorders, Early Child Development and Care, DOI:10.1080/03004430.2011.616931

[31] Samadi, S. A, Mcconkey, R, \& Bunting, B. (2014). Parental wellbeing of Iranian families with children who have developmental disabilities. Research in Developmental Disabilities. , 35, 1639-1647.

Samadi,S.A., McConkey, R., \& Bunting, B. (2014). Parental wellbeing of Iranian families with children who have developmental disabilities. Research in Developmental Disabilities. 35, 1639-1647.

[32] Tudge, J.R.H, Mokrova, I, Hatfield, B.E, \& Karnik, R.B. . ((2009). ). Uses and Misuses of Bronfenbrenner's bioecological theory of human development. Journal of Family Theory \& Review,. doi: 10.1111/j.1756-2589.2009.00026.x, 1, 198-210. 
Tudge, J.R.H., Mokrova, I., Hatfield, B.E., \& Karnik, R.B. (2009). Uses and Misuses of Bronfenbrenner's bioecological theory of human development. Journal of Family Theory \& Review,1, 198-210. doi: 10.1111/j.1756-2589.2009.00026.x

[33] Turnbull, A. P, Blue-banning, M, \& Turbiville, V. \& J. Park ((1999). From Parent Education to Partnership Education: A Call for a Transformed Focus. Topics in Early Childhood Special Education, , 19(3), 164-171.

Turnbull, A. P., Blue-Banning, M., Turbiville, V. \& J. Park (1999). From Parent Education to Partnership Education: A Call for a Transformed Focus. Topics in Early Childhood Special Education, 19(3):164-171.

[34] World Health Organisation (WHO) ((2001). International Classification of Functioning, Disability and Health (ICF) Short version. WHO. Geneva. Switzerland.

World Health Organisation (WHO) (2001). International Classification of Functioning, Disability and Health (ICF) Short version. WHO. Geneva. Switzerland.

[35] Zimmerman, M. A. (2000). Empowerment theory: Psychological, organizational, and community levels of analysis. In J. Rappaport and E. Seldman (eds.), Handbook of Community Psychology. New York: Plenum.

Zimmerman, M.A. (2000). Empowerment theory: Psychological, organizational, and community levels of analysis. In J. Rappaport and E. Seldman (eds.), Handbook of Community Psychology. New York: Plenum. 